\title{
A Prospective Study of Closed Comminuted Osteoporotic Metacarpal Shaft Fractures Treated with Locking Mini Plates in a Tertiary Care Hospital
}

\section{Venkataramana Rao $\mathbf{M}^{1}$, Manjunath $\mathrm{J}^{2}$, Kore Aditya Basawaraj ${ }^{3 *}$, Sachin S Nimbargi ${ }^{1}$, Pavan Patil ${ }^{4}$ and Druva $\mathrm{V}^{5}$}

${ }^{1}$ Professor, Department of Orthopaedics, SSIMS and RC, Karnataka, India

${ }^{2}$ Professor and HOD, Department of Orthopaedics, SSIMS and RC, Karnataka, India

${ }^{3} J u n i o r$ Resident, Department of Orthopaedics, SSIMS and RC, Karnataka, India

${ }^{4}$ Assistant Professor, Department of Orthopaedics, SSIMS and RC, Karnataka, India

${ }^{5}$ Senior Resident, Department of Orthopaedics, SSIMS and RC, Karnataka, India

*Corresponding Author: Kore Aditya Basawaraj, Junior Resident, Department of

Orthopaedics, SSIMS and RC, Karnataka, India.
Received: February 08, 2021

Published: February 27, 2021

(C) All rights are reserved by Kore Aditya

Basawaraj., et al.

\begin{abstract}
Background: Fractures of hand bones are the most common fractures encountered and management of the same differs across the world. Multiple factors are responsible for the variability in management. Less expensive methods of hand fractures treatment are followed in developing countries. Fractures of the hand bones accounts between $20 \%-30 \%$ of all visits to the emergency room following trauma due to assault, road traffic accidents etc.

Methods: A prospective study was carried out from October 2018 to October 2020 in department of orthopaedics, SS institute of medical sciences, Davangere, Karnataka, India. A total of 30 cases with metacarpal fractures were treated surgically with locking mini plate and screws and were followed up at the end of 1, 2, 4 and 6 months and evaluated with ASSH-TAF score.

Results: This study compraises of 30 patients. 7 patients had multiple metacarpal fractures (23\% cases). In 19 patients (63\%) right hand was involved. 23 out of 30 patients were males (77\%). 100\% results achieved in patients who underwent open reduction and internal fixation with locking compression plate for unstable metacarpal fracture.

Conclusions: Locking compression plates are a satisfactory method for treating comminuted, unstable and osteoporotic metacarpal and phalangeal fractures where alternative methods of fixation are least effective, plating provides the rigid stable fixation which sustains load without non success allowed early mobilization and gained good practical outcome in contrast to other methods.
\end{abstract}

Keywords: Fractures; Periosteum; Stiffness

\section{Introduction}

Fractures of hand bones are the most common fractures encountered and management of the same differs across the world. Multiple factors are responsible for the variability in management. Less expensive methods of hand fractures treatment are followed in developing countries. Fractures of the hand bones accounts between $20 \%-30 \%$ of all visits to the emergency room following trauma due to assault, road traffic accidents etc. [1]. Metacarpal fractures are mostly ignored and ends in dysfunction and permanent deformity [2,3]. Deformity and/or stiffness are the most common complications of hand bone fractures [4]. In treatment of fractures of hand bone functional outcome matters 
than mere fracture healing [5]. Achieving good bone union and minimising joint and tendon complications are possible by a stable bony constructs which allows early tendon gliding and joint movement. Some studies prove that plating for communitted fracture are superior to other fixation methods [6]. This study involves assess outcome of metacarpal shaft fractures treated with locking miniplates and screws [7].

\section{Materials and Methods}

A prospective study was carried out from October 2018 to October 2020 in department of orthopaedics, SS institute of medical sciences, Davangere, Karnataka, India. A total of 30 cases with metacarpal fractures were treated surgically with locking mini plate and screws and were followed up at the end of 1, 2, 4 and 6 months and evaluated with ASSH-TAF score. Patients above 18 years with closed metacarpal fractures and willing to be included in the study were taken into account. Thorough history with demographic data is collected following admission to assess mode of injury and other co-morbidities.

\section{Surgical procedure}

In all the cases tourniquet is used before surgery. Surgical approach is through dorsal incision on radial the $1^{\text {st }}$ and $2^{\text {nd }}$ metacarpal, ulnar border for the fifth metacarpal. Dorsal longitudinal incision made between $3^{\text {rd }}$ and $4^{\text {th }}$ metacarpal to approach them. Anatomical reduction is achieved following retraction of extensor tendons. Reduction is maintained using point reduction forceps or a stabilizing $\mathrm{K}$ wire. Based on the fracture pattern plate configuration were chosen and fixed with screws. Soft tissue dissection is done with extra care to achieve adequate soft tissue coverage (periosteum) over the plate to prevent irritation to overlying extensor tendon. Wound closed without drain following thorough washing. Cock-up slab used for hand splinting.

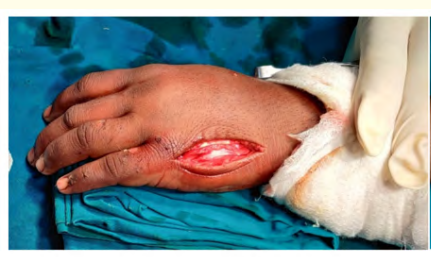

(Incision for $5^{\text {th }}$ metacarpal fracture)

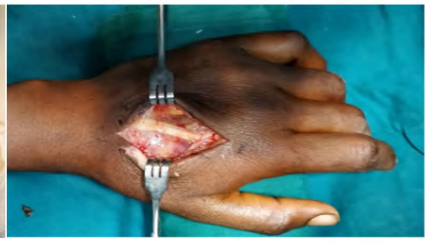

(Visualization of extensor tendon)
Figure 1

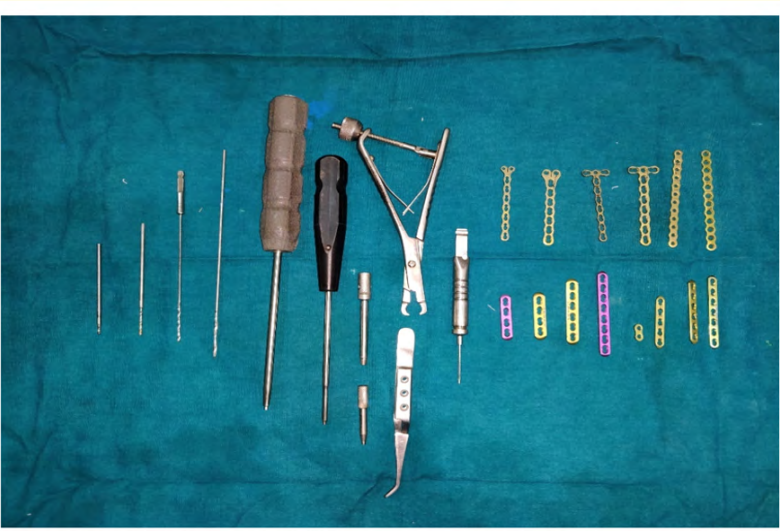

(Metacarpal LCP system)

Figure 2

Clinical and radiological photograph

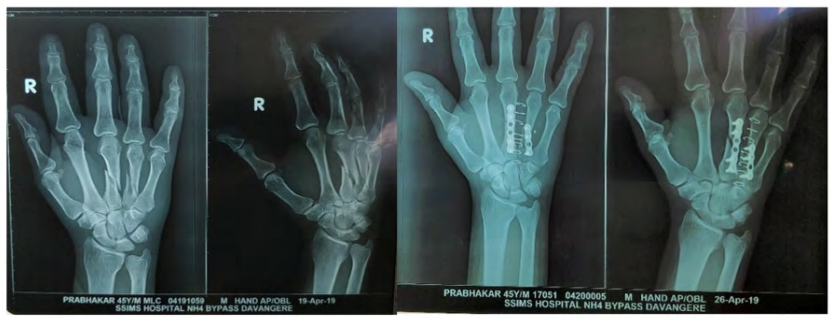

Figure 3: $3^{\text {rd }}$ and $4^{\text {th }}$ short oblique metacarpal fracture Immediate post-operative xray with LCP in-situ.

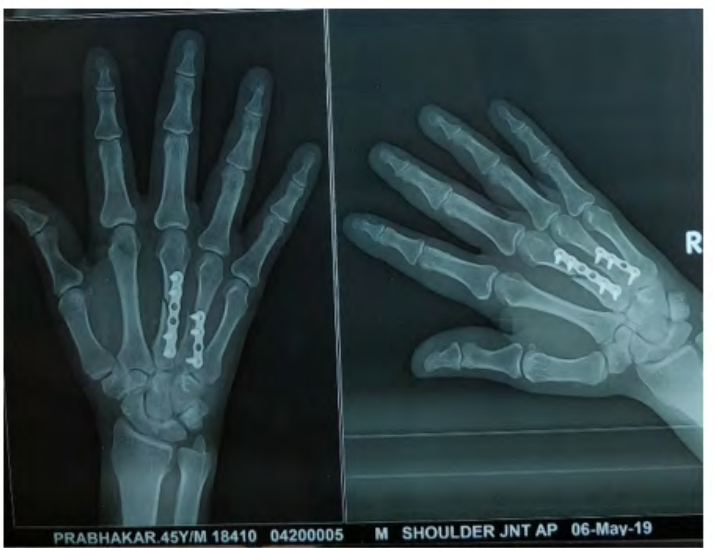




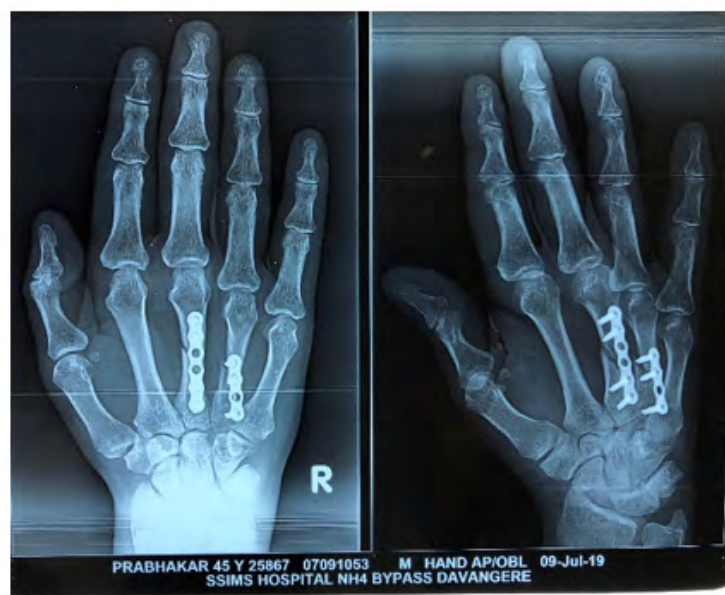

Figure 4: 4 weeks follow-up x-ray.

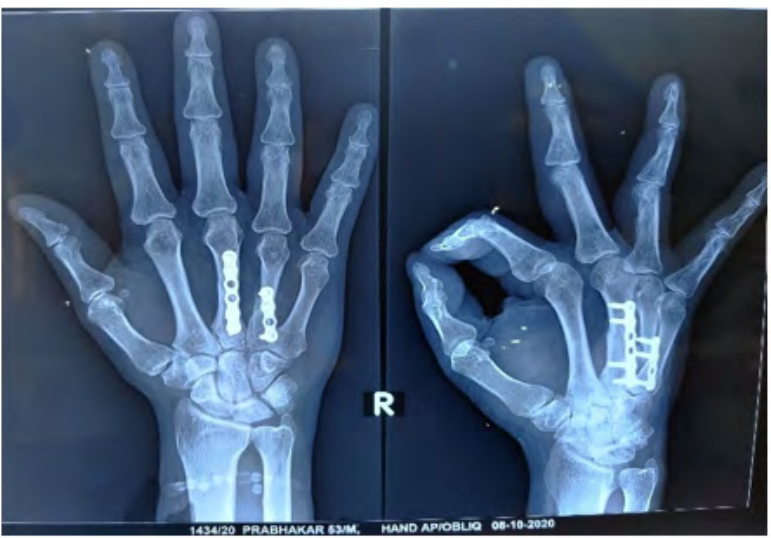

Figure 5: 8 weeks follow-up x-ray.

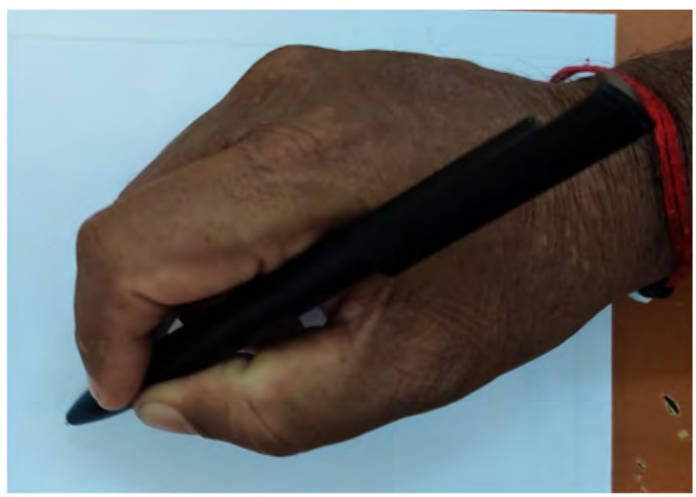

Figure 6: $1 \frac{1}{2}$ years united 3 and $4^{\text {th }}$ metacarpal fracture with LCP insituPinch strength.
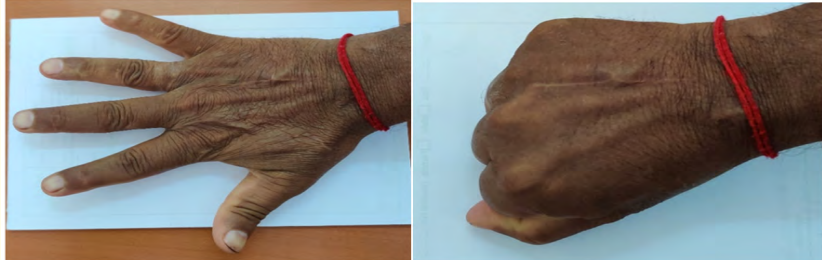

Figure 7: Extension and Flexion of MCP and IP joints.

Case 2

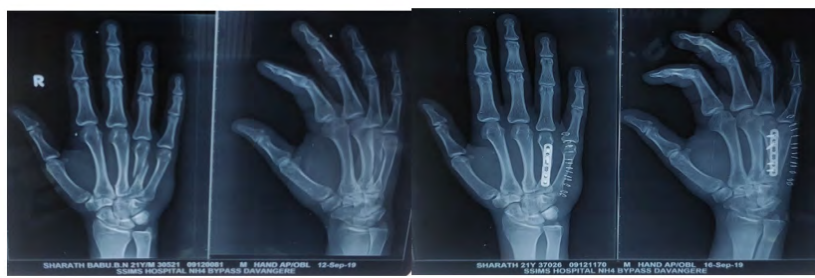

Figure 8: $4^{\text {th }}$ right metacarpal oblique fracture Immediate post op.

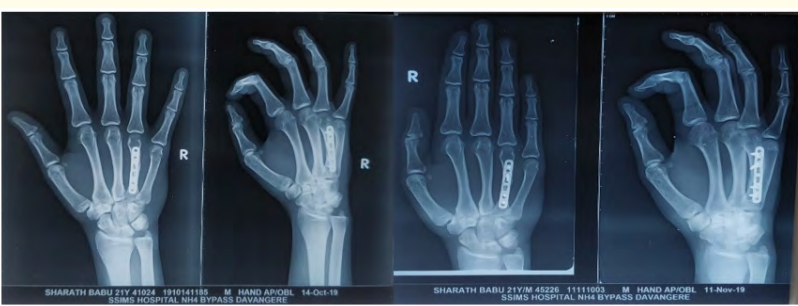

Figure 9: 4 weeks post op xray 8 weeks post op xray.

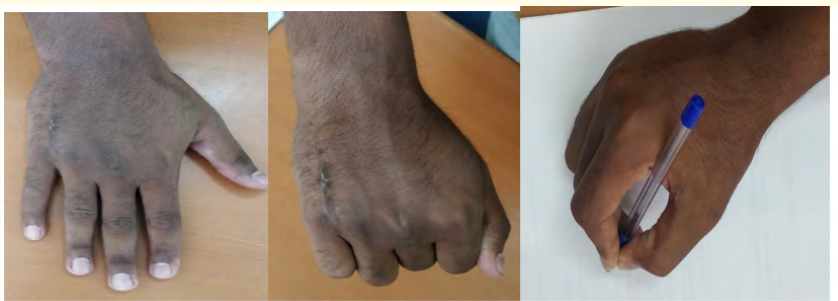

Figure 10: Extension and flexion of MCP and IP joints Pinch strength. 
A Prospective Study of Closed Comminuted Osteoporotic Metacarpal Shaft Fractures Treated with Locking Mini Plates in a Tertiary Care Hospital

\section{Results}

This study compraises of 30 patients. 7 patients had multiple metacarpal fractures (23\% cases). In 19 patients $(63 \%)$ right hand was involved. 23 out of 30 patients were males (77\%). 100\% results achieved in patients who underwent open reduction and internal fixation with locking compression plate for unstable metacarpal fracture. Healing of transverse and comminuted fractures takes place around 8 weeks c0mpared to 6 weeks for spiral and oblique fractures. ASSH (American Society for Surgery of the Hand) TAF (Total Active Flexion) score result analysis was outstanding in 22 patients (73\%), good in 6 patients $(20 \%)$, poor in 2 patient (6\%). The overall results are satisfactory.3 patients developed superficial wound infection. Superficial infection resolved with regular dressing and antibiotics in above 2 cases. Physiotherapy was fairly help full in 3 cases with multiple metacarpal fractures leading to stiffness. Due to lack of coverage of the plate with soft tissue (periosteum) for free gliding of overlying extensor tendon, 3 patients developed tendon irritation in our study. Displacement of fractures is not seen in any of the cases. Implant breakage and implant removal was not an issue in any of the cases.

\section{Discussion}

Conservative method of protective splinting followed by early mobilization was successfull in most of the metacarpal fractures $[8,9]$. Unsatisfactory functional results were seen in small percentage of metacarpal fractures following closed reduction. And those are the cases indicated for open reduction and internal fixation [10]. James., et al. [11] study revealed loss of function in seen in $2 / 3^{\text {rd }}$ of fingers treated with closed reduction. These unstable fractures are mostly treated by open reduction and internal fixation with $\mathrm{K}$ wire which mostly leads to less rigid fixation and rotational unstability and also there is increased association of persistent infections. External fixator are used to fix metacarpal fracture [12]. Report by Shehadi., et al. [13] showed that with the use of external fixator metacarpal fractures there is $100 \%$ return of total range of motions. This is useful in compound metacarpal fractures with bone loss. Difficulty in applying the fixator and loosening of the construct due to pin tract infection leading to loss of fixation have discouraged regular use of external fixator. Satisfactory outcome of unstable metacarpal and phalangeal fracture treated with AO mini plate are supported by literature studies [14]. Souer., et al. [15] study revealed good functional outcome by total active motion more than 220 degree in 20 patients following plate fixation in closed unstable metacarpal fractures. Dabezies Schutte [16] study revealed that complications has not resulted any morbidities in 27 unstable metacarpal fractures treated with plate fixation. Like other studies negligible complication seen. In unstable metacarpal fractures, plate fixation is a superior option on basis of several grounds [17].

- They impart stable fixation permitting early mobilization of fingers

- Shortening corrected by plating reinstitute the ability of interossei muscle thereby detaining the grip strength of hand.

- In most of multiple metacarpal severe soft tissue injury is seen.

Good functional results are seen with locking compression plates in the treatment of unstable metacarpal fractures thus preventing stiffness. All the cases showed bone union following treatment with locking compression plate. ASSH (American Society for Surgery of the Hand) TAF (Total Active Flexion) score result analysis was outstanding in 22 patients (73\%), good in 6 patients (20\%), poor in 2 patient (6\%). Early movements of fingers due to stable and rigid fixation resulted in overall good functional result and prevented stiffness. Smaller sample size and absence of control group are the limitations of the study.

\section{Conclusion}

Locking compression plates are a satisfactory method for treating comminuted, unstable and osteoporotic metacarpal and phalangeal fractures where alternative methods of fixation are least effective, plating provides the rigid stable fixation which sustains load without non success allowed early mobilization and gained good practical outcome in contrast to other methods. Thorough assessment clinically and radiologically, vigilant preoperative planning, conscientious dissection, accuracy in surgical technique (coverage of plate with periosteum) and selecting the correct implant (locking compression plates) are supreme important in achieving good results and keep down the complications.

\section{Bibliography}

1. Gupta R., et al. "Evaluation of surgical stabilization of metacarpal and phalangeal fractures of hand". Indian Journal of Orthopaedics 41.3 (2007): 224-229.

2. De Jonge JJ., et al. "Fractures of the metacarpals. A retrospective analysis of incidence and etiology and a review of the Englishlanguage literature". Injury 25 (1994): 365-369. 
3. Kamath JB., et al. "Current concepts in managing fractures of metacarpal and phalanges". Indian Journal of Plastic Surgery 44 (2011): 203-211.

4. Barton NJ. "Fractures and joint injuries of hand". In: Wilson JN editor. Watson - Jones fractures and joints injures. 6th edn Vo. II Churchill Livingstone Pvt. Ltd, New Delhi (1996): 739-788.

5. Brenwald J. "Bone healing in the hand". Clinical Orthopaedics and Related Research 214 (1987): 7-10.

6. Wong Hing-Cheong., et al. "Stainless Steel 2.0-mm Locking Compression Plate Osteosynthesis System for the Fixation of Comminuted Hand Fractures in Asian Adults 2011". Journal of Orthopaedics, Trauma and Rehabilitation 15 (2011) 57-61.

7. Ozer K., et al. "Comparison of intramedullary nailing versus plate-screw fixation of extra-articular metacarpal fractures". Journal of Hand Surgery (American Volume) 33.10 (2008): 1724-1731.

8. Barton N. "Conservative treatment of articular fractures in the hand". Journal of Hand Surgery (American Volume) 14 (1989): 386-390.

9. Wright TA. "Early mobilization in fractures of the metacarpals and phalanges". Canadian Journal of Surgery 11 (1968): 491498.

10. Amadio PC. "Fractures of the hand and the wrist". In: Jupiter JB (ed) Flynn's hand surgery. Williams and Wilkins, Baltimore (1991): 122-185.

11. James JIP. "Fractures of the proximal and middle phalanges of the fingers". Acta Orthopaedica Scandinavica 32 (1962): 401412.

12. Parsons SW., et al. "External fixation of unstable metacarpal and phalangeal fractures". Journal of Hand Surgery 17 (1992): 151-155.

13. Gonzalez MH., et al. "Flexible intramedullary nailing for metacarpal fractures". Journal of Hand Surgery 20 (1995): 382-387.

14. Trevisan C., et al. "Low severity metacarpal and phalangeal fractures treated with miniature plates and screws". Archives of Orthopaedic and Trauma Surgery 124 (2004): 675-680.
15. Souer JS and Mudgal CS. "Plate fixation in closed ipsilateral multiple metacarpal fractures". Journal of Hand Surgery European 33.6 (2008): 740-744.

16. Dabezies EJ and Schutte J. "Fixation of metacarpal and phalangeal fractures with miniature plates and screws". Journal of Hand Surgery (American Volume) 11 (1986): 283288.

17. Aswini Soni and Anmol Gulati JL "Outcome of closed ipsilateral metacarpal fractures treated with minifragment plates and screws: a prospective study". Journal of Orthopaedics and Traumatology 13 (2012): 29-33.

\section{Assets from publication with us}

- Prompt Acknowledgement after receiving the article

- Thorough Double blinded peer review

- Rapid Publication

- Issue of Publication Certificate

- High visibility of your Published work

Website: www.actascientific.com/

Submit Article: www.actascientific.com/submission.php

Email us: editor@actascientific.com

Contact us: +919182824667 